\title{
Drug Injecting Practice among Adolescents in Pokhara Sub-Metropolitan City, Nepal
}

\author{
${ }^{1}$ Niranjan Shrestha \\ 1 School of Health and Allied Sciences, Pokhara University, Kaski, Nepal.
}

\begin{abstract}
Drug injecting, a growing public health problem among adolescents which is a major concern of society as well as stakeholders. Objective of the study was to assess practice of injecting drug among adolescents in Pokhara. An institution based cross-sectional quantitative study among 15-19 year school adolescents in higher secondary levels and certificate levels was selected from 16 academic institutions within the valley using random sampling technique. A semi structured, self-administered anonymous questionnaire was used to collect the information from September to December in 2009. Data were analyzed by using Statistical Package for Social Sciences. Altogether 857 respondents were included in the study: $58.8 \%$ male and $41.2 \%$ female. Mean \pm standard deviation of first drug intake age was $14.70 \pm 2.751$ years respectively. The average number of times the drug injects was found as 6.38 times/week. Prevalence of risky injecting behavior was found although $71.4 \%$ of respondent's sterilized equipments before sharing. Kruskal Wallis test showed no significant difference on an average drug intake among different disciplines of institution $(P=0.515)$; and a similar type of conclusion among type of institution $(P=0.520)$. Males were found to have engaged in injecting drug with polydrug in the adolescent period. Percentages of injecting drug users along with risk behavior found to be decreasing among injectors. Specific interventional program should be designed to promote adolescent health behavior.
\end{abstract}

Key words: Injecting drugs, Adolescent, Sharing equipment, Health behavior:

Corresponding address: Niranjan Shrestha, School of Health and Allied Sciences, Pokhara University, Kaski, Nepal. E-mail:nrjanstha@yahoo.com

\section{INTRODUCTION}

Adolescents as individuals in the age group $10-19$ years, periods roughly correspond with the phases in physical, social and psychological development in the transition from childhood to adulthood. ${ }^{1}$ Drugs such as cannabis and alcohol were found to be used traditionally in Nepal for centuries as part of the cultural norms. Now a day various types of drugs are used which have been shifted from cannabis to synthetic opiates and chemical substances since last few decades create major social problems and its control a challenge for the government. A brief scenario showed the highest proportion of the drug users are found in Kathmandu valley $(17,458)$ followed by Kaski (5112) where teenagers of age group 15 - 19 years comprise $21.6 \%$ of the total drug users and nearly three fourth $(73.1 \%)$ drug users have experience of first time drug intake before they reach 20 years. ${ }^{2}$

The mode of drug usage has changed from smoking and chewing to injecting. Previous studies showed that about $85 \%$ of injecting drug users (IDUs) report illicit non injection drug use prior to initiating injection use. ${ }^{3}$ Injecting drug use is a growing problem among adolescents and it is a great concern of every stakeholder. It has been regarded as the most dangerous route of drug administration, not only because of the risk of drug overdose, but also because of infection and other diseases associated with injecting behavior. ${ }^{4}$ Use of contaminated equipment during injecting drug use represents an especially efficient means of HIV transmission, often leading to the rapid spread of HIV infection in localized networks of drug users. ${ }^{5}$ Adolescents of today are exposed to the risk of being victims of drugs and HIV/AIDS which was quite unknown to their predecessors a few decades ago.

The number of IDUs worldwide was estimated as approximately 13.2 million with the estimates of IUDS prevalence available for 130 countries. ${ }^{6}$ A study showed that one eighth of the injecting drug users (13\%) in Pokhara who were contacted for in-depth study about their injecting practice, networking and sexual behavior comprised of the adolescents for the age group $10-19$ years, $3(12.5 \%)$ males and no females were found on injecting drugs. ${ }^{\text {? }}$

A study on IUDs in Kathmandu showed over half of the 296 participants $(51 \%)$ injected the drugs with a needle or syringe previously used by another and of these, $106(70 \%)$ engaged in sharing injection equipment with multiple persons. ${ }^{8}$ Frequency of sharing with others was also associated with intimacy of relationship to the subject. Almost two-thirds of the sample had shared some sort of injecting equipment during the previous year. ${ }^{9}$ Borrowing and lending of injecting equipment, as well as non-sterile practices in the preparation, distribution and injecting of drugs has been documented frequently in Nepal. ${ }^{10}$

The trend of taking mixed drugs and the frequency of injecting per day was in the increasing trend. The sharing of used needles was in decreasing trend; however there were still some IDUs who share needles/syringes among the injecting partners. ${ }^{11}$

More than one fourth of the IDUs in study area reported that they inject three to four times per day. The informants had 
reported different techniques for cleaning the used needles. The almost of techniques were medically inadequate to prevent the blood born transmissions. ${ }^{12}$ The percentage of IDUs more than once in a day was decreasing along with high risk behavior such as injecting with previously used needles significantly decreased, from $21 \%$ to $5 \%$ in Pokhara. ${ }^{10,13}$ Injecting behavior has been declining, this is countered by data suggesting that a growing proportion of people who injects drugs start injecting at a young age (below 20 years), and they inject for a longer time (longer average duration of injection) ${ }^{14}$ Nepal is currently experiencing a concentrated epidemic of HIV among selected high risk population in the country shows high prevalence $22 \%$ among injecting drug users in Pokhara. ${ }^{15}$ Evidence has accumulated, however, to show that drug injectors are lessening their risks of HIV/ AIDS by reducing needle sharing, suggesting that increasing attention should be paid to sexual behavior. ${ }^{16}$ Young injectors may be at more risk than non-injectors because the people with whom they have sex are often themselves injectors who sometimes share needles. It becomes particularly important to convey to this group, and groups like them, the double risk that may be involved. ${ }^{17}$

For the purpose of this study, injecting drug is defined as the drug taken by syringe or needle or by any equipment in the body and was not considered the drug injected for medical purpose or treatment of an illness.

\section{METHODS}

An institution based cross-sectional quantitative study was conducted to assess practice of injecting drug use among adolescents (15-19 years) of Pokhara Sub Metropolitan city. Assuming proportion of adolescents involved in injecting drug $50 \%$ and maximum tolerable error of $5 \%$, the sample size was calculated as 384 . The sample was doubled to eliminate design effects. Thus, minimum required samples were 770. Academic institutions running proficiency level courses and equivalent $(10+2)$ were stratified according to type of institution (Government, Private and Community) and then by disciplines (Science and Technology, Management, Humanities and Social Sciences, and Education) within the institutions. Sixteen academic institutions were selected randomly from alphabetically arranged list of 49 institutions. Adolescents studying in higher secondary levels and certificate levels constituted study population and information adjusted for them. Participants were selected from these institutions with all students of a single class. All adolescents of the selected grades were selected to ensure validity thus the total sample size was 857 . Pretested, semi structured, a self administered anonymous questionnaire was administered with instructions by male and female investigators for respective gender after receiving a verbal consent of the participants during September to December 2009. Filled questionnaire in a sealed envelope was collected without any identity for confidentiality from the respondent in the next day. The collected data were analyzed by using Statistical Package for Social Sciences.

\section{RESULTS}

Findings from the study were summarized as below. Depicts the distribution of respondents along with disciplines and types of institutions (Table 1).

Table 1: Distribution of respondents

\begin{tabular}{|l|c|c|c|c|}
\hline \multirow{2}{*}{ Discipline } & \multicolumn{3}{|c|}{ Type of institution } & \multirow{2}{*}{ Total } \\
\cline { 2 - 4 } & Government & Private & Community & \\
\hline Science and technology & 100 & 150 & 61 & 311 \\
\hline Management & 59 & 146 & 105 & 310 \\
\hline Humanities and social sciences & 49 & 0 & 68 & 117 \\
\hline Education & 61 & 0 & 58 & 119 \\
\hline Total & 269 & 296 & 292 & 857 \\
\hline
\end{tabular}

A response of $837(97.67 \%)$ to study prevalence on injecting drug is presented in (Table 2).

Table 2: Gender wise distribution of respondents

\begin{tabular}{|c|c|c|c|}
\hline \multirow{2}{*}{ Gender } & \multicolumn{2}{|c|}{ Have you ever injected drugs? } & \multirow{2}{*}{ Total } \\
\cline { 2 - 3 } & Yes & No & \\
\hline Male & 10 & 480 & 490 \\
\hline Female & 0 & 347 & 347 \\
\hline Total & 10 & 827 & 837 \\
\hline
\end{tabular}

Injecting drug was found to be indulged by only males in the study. Twenty participants did not respond the question. The minimum and maximum age was 8 and 17 years respectively with the mean \pm standard deviation of age was found to be $14.70 \pm 2.751$ years as they reported for first intake.

The main reasons for using drugs are love tragedy (50\%) and rest in equal percent for curiosity, study problem, family problem, the combination of more than one problem was recorded in the study.

Majorities of the drug users were found in community institution ( $50 \%$ ) followed by private $(30 \%)$ and government $(20 \%)$. Similarly $50 \%$ of the drug users were found in Faculty of Science and Technology followed by Management (30\%) and Humanities and Social Sciences (20\%). Drug users were not reported in the Faculty of Education. Kruskal Wallis test showed no significant difference on an average drug intake among different disciplines of institution $(\mathrm{P}=0.515>0.05)$; and a similar conclusion among type of institution $(\mathrm{P}=0.520$ $>0.05)$.

Out of the exposed drug users, 6 were found that they had switched from non injection mode to injection mode to take drug. The minimum and maximum number of times the drug users inject per week was recorded as once/ week and 14 times/ week. The mean number of times was found as 6.38 times /week. About $90.0 \%$ of the drug users would get company by their friends while taking drug with more than one type of drug at a time and $10.0 \%$ users used only one type of drug. The names of the drug they reported in their 
words for taking orally as well as for injecting purpose are Black, Heroine, Brown sugar, Weeds, Norfin/TD, Marijuna, Nitrosun, Brown, Gajja, Cocaine, Tablet (vat), Hasish, Charesh, Norphin, Phenargon, Dizepam which are taken in public and sound places.

Six out of ten $(60.0 \%)$ users mentioned that the source of the drug they obtained is from their drug user friends followed by medical store, mobile drug seller and other. Rest of the users received not only from the mentioned source but also from the possible combination of one or more sources.

It was found that $40.0 \%$ of the injecting drug users exchanged their syringe or needle that had previously used by someone else. Result showed that nearly three out of every four $(71.4 \%)$ of the responded used any one of the sterilization method they have known out of which the percent of boiled is 28.6. Although majorities responded that they sterilized the equipment before sharing it, the percent of done nothing was also noticeable i.e. 28.6 percent

Those who exposed to take drug, $40 \%$ of the drug users were found that they had tried for treatment and rest not. Seven $(70.0 \%)$ had tried to stop taking drug and not rest, which shows the percentage of injecting drug users has been decreasing among the injectors. Summarized the situation of the drug users who had stop taking drug and tried for treatment (Table 3).

Table 3: Situation of injecting drug users

\begin{tabular}{|c|c|c|c|}
\hline \multirow{2}{*}{$\begin{array}{c}\text { Have you ever tried } \\
\text { to stop taking drug? }\end{array}$} & \multicolumn{2}{|c|}{$\begin{array}{c}\text { Have you ever tried } \\
\text { for treatment? }\end{array}$} & \multirow{2}{*}{ Total } \\
\cline { 2 - 3 } & Yes & No & \\
\hline Yes & 4 & 3 & 7 \\
\hline No & 0 & 3 & 3 \\
\hline Total & 4 & 6 & 10 \\
\hline
\end{tabular}

DISCUSSION

In the study, $1.20 \%$ male adolescents reported that they had injected drugs. A similar study conducted on the age group $10-19$ years, $3(12.5 \%)$ males and no females were found on injecting drugs in Pokhara. ${ }^{7}$ Among the drug users reported in the study, exactly four out of every ten of the respondent stopped in injecting drug. This showed that number of drug injecting users has been declined within among the injectors. A consistency in the results was obtained and the proportion of adolescents involved in injecting drug has found to be decreasing in Pokhara. This might be due to various awareness and behavioral programs conducted by different institutions. Central Bureau of Statistics (CBS) reported teenagers in the age group $15-19$ years comprise $21.6 \%$ of the total drug users which is very high in comparison to study area. This is due to the overall distribution of drug addict is not uniform within Nepal and also the proportion of the adolescents using drug by any other method is not studied in this research. Drug users have experienced drug intake for first time before they reach 20 years $^{2,14}$ was justified for Pokhara also due to the maximum age of first drug intake was reported as 17 years in the study means a consistency result in the age of first drug intake. The statement, if a person uses a particular drug, he/ she is likely also to initiate the use of other drugs ${ }^{18}$ seems reliable here also since the majority of injectors were found using more than one type of a drug at a time.

Exactly four out of ten of the drug user were found to have exchanged syringe which was low than non-sharing users justifies the borrowing and lending of injecting equipment ${ }^{10}$ takes place and consistent with the sharing of used needles was in decreasing trend. ${ }^{11,13}$ Nearly three out of every four $(71.4 \%)$ of the respondents cleaned their needle and syringe before injecting that had been used by someone else where the percentage of boiled is 28.6 which is more than only $7 \%$ of the total study respondents reported that they boiled the needles and syringes in water ${ }^{7}$ this may be due to adolescents of the higher secondary levels were more aware about the possible transmissions of the disease than the general people as a result an increase in the method of sterilization before sharing needles and syringe. This difference is also due to different location selected and a record of a decade ago.

\section{CONCLUSION}

Males were found to have engaged in injecting drug with polydrug in the adolescent period i.e. before 15 years of age on an average. Although, percentages of injecting drug users along with risk behavior found to be decreasing among injectors, injecting patterns continue to cause concern. Specific interventional program should be designed to promote adolescent health behavior.

\section{ACKNOWLEDGEMENT}

I would like to thank Faculty of Science and Technology, Pokhara University for providing the research grant. Special thank goes to principal, campus chief, asst. campus chief, program coordinators of the selected higher secondary school/campus on the study for making environment during the process of data collection. Thanks to all the respondents for their response.

\section{REFERENCES}

1. WHO. The Health of Young People: A challenge and a promise. Geneva: World Health Organization 1993.

2. CBS. Summary Report of the Survey on Hard Drug Users in Nepal 2063. Central Bureau of Statistics 2007. 
3. Fuller CM, Vlahov D, Ompad DC, Shah N, Arria A, Strathdee SA. High-risk behaviors associated with transition from illicit non-injection to injection drug use among adolescent and young adult drug users: A case-control study. Drug Alcohol Depend 2002; 66(2):189-98.

4. Gossop M, Griffiths P, Powis B, Strang J. Severity of dependence and route of administration of heroin, cocaine and amphetamine. British Journal of Addiction 1992 Nov; 87(11),1527-1536.

5. UNAIDS. 2008 report on the global AIDS epidemic. [Cited 2012 Mar 16] Available at: www.unaids.org/en/KnowledgeCentre/HIVData/ GlobalReport/2008/2008_Global_report.asp

6. Aceijas C, Stimson GV, Hickman M, Rhodes T; United Nations Reference Group on HIV/AIDS Prevention and Care among IDU in Developing and Transitional Countries. Global overview of injecting drug use and HIV infection among injecting drug users. AIDS. 2004 Nov; 18(17):2295-303.

7. MoHP. Adolescent health and development in Nepal, Status, Issues, Programmes and Challenges, A Country Profile. Ministry of Health and Population, 2005.

8. Poudel KC, Poudel TK, Yasuoka J, Joshi AB, Jimba M. Correlates of sharing injection equipment among male injecting drug users in Kathmandu, Nepal. Int J Drug Policy 2010 Nov; 21(6):507-10.

9. Gossop M, Griffiths P, Powis B, Williamson S, Fountain J, Strang J. Continuing drug risk behaviour: shared use of injecting paraphernalia among London heroin injectors. AIDS Care: Psychological and Socio-medical Aspects of AIDS/HIV 1997; 9(6): 651-660.

10. WHO. Report on people who inject drugs in the South-East Asia Region. World Health Organization 2010.

11. Stone N, Ingham R, Simkhada P. Knowledge of Sexual Health Issues among Unmarried Young People in Nepal. Asia-Pacific Population Journal 2003; 18(2):33-54

12. FHI. Injecting and Sexual Behaviours of Injecting Drug Users in Pokhara. Kathmandu: Family Health International 2004.

13. FHI. Integrated Biological and Behavioral Surveillance among Injecting Drug Users (IDUs) in Kathmandu, Pokhara, Eastern Terai and Western to Far Western Terai 2009 Round IV. Family Health International/Nepal 2009.

14. Nepal, FHI. Integrated biological and behavioural survey among injecting drug users in the Kathmandu Valley. Kathmandu: New Era, SATCS, Family Health International 2007.

15. CREHPA. Injecting and sexual behaviors of injecting drug users in Pokhara, Nepal. Center for research on environment health and population activities Nepal 2004.

16. Rhodes T, Quirk A. Where is the sex in harm reduction? International Journal of Drug Policy 1995; 6:78-82.

17. Loxley W. Double risk: young injectors and sexual relationships. Sex Relat. Ther. 2000; 15(3):297-310.

18. Yamaguchi K, Kandel DB. Patterns of drug use from adolescence to young adulthood: II. Sequences of progression. Am J Public Health. 1984 July; 74(7):668-672. 